\title{
Effect of Thermal Ageing Characteristics of Al-Si-Fe/Sic Particulate Composite Synthesized by Double Stir Casting
}

\author{
V.S. Aigbodion* and S.B. Hassan \\ * Department of Metallurgical and Materials Engineering, Ahmadu Bello University, Samaru, Zaria, Nigeria
}

Received 3 June 2009; accepted 6 September 2009

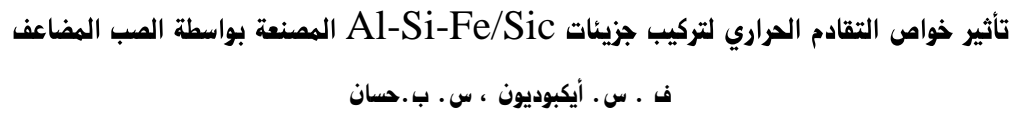

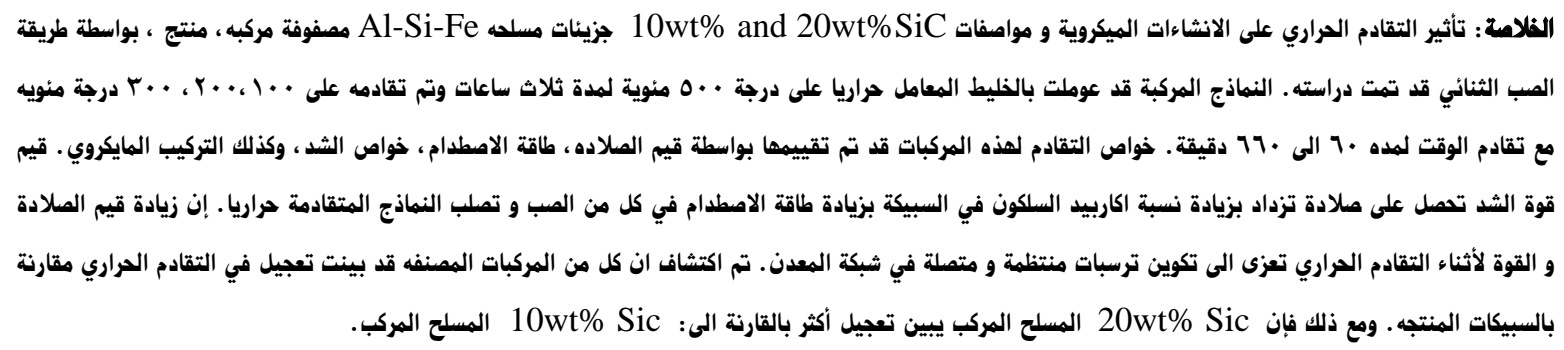

الهزدات الهناهية: Al-Si-Fe/Sic ، تقادم حراري، مركب، خواص ميكانيكية، تركيب ما يكروين ترسيب.

\begin{abstract}
The effect of thermal ageing on the microstructure and properties of $10 \mathrm{wt} \%$ and $20 \mathrm{wt} \% \mathrm{SiC}$ particulate reinforced Al-Si-Fe matrix composite, produced by double stir casting route, have been studied. The composite samples were solution heat-treated at $500^{\circ} \mathrm{C}$ for 3 hrs and aged at 100,200 , and $300^{\circ} \mathrm{C}$ with ageing time between 60 and 660 minutes. The ageing characteristics of these grades of composite were evaluated using hardness values, impact energy, tensile properties and microstructure. The tensile strength, yield strength, hardness values increased as the percentage of silicon carbide increased in the alloy with decreased impact energy in both the as-cast and thermally age-hardened samples. The increases in hardness values and strength during thermal ageing are attributed to the formation of coherent and uniform precipitation in the metal lattice. It was found that both grades of composites showed acceleration in thermal ageing compared to the monolithic alloy. However, the $20 \mathrm{wt} \% \mathrm{SiC}$ reinforced composite showed more acceleration compared to $10 \mathrm{wt} \% \mathrm{SiC}$ reinforced composite.
\end{abstract}

Keywords: Al-Si-Fe/SiC, Thermal ageing, Composite, Mechanical properties, Microstructure and precipitation

\section{Introduction}

In recent years, the development of metal matrix composites (MMCs) has been receiving worldwide attention on account of their superior strength and stiffness in addition to high wear resistance and creep resistance compared to their corresponding wrought alloys. The ductile matrix permits the blunting of cracks and stress concentrations by plastic deformation and provides a material with improved fracture toughness (Aigbodion. V.S, 2007).

The present trend, therefore, seems to be towards the development of discontinuously reinforced metal matrix composites which are gaining widespread acceptance primarily because they have recently become available at a

*Corresponding author’s e-mail: aigbodionv@yahoo.com relatively low cost compared to uni-and multi-directional continuous-fiber reinforced MMCs and the availability of standard or near-standard metal working methods which can be utilized to form these MMCs (Aigbodion, V.S, 2007, and Clyne, T. W, 2000).

Nowadays, research all over the globe is focusing mainly on Aluminium (Aigbodion, V.S., 2007, and Yaro, S.A., et al. 2006) because of its unique combination of good corrosion resistance, low density and excellent mechanical properties. The unique thermal properties of Aluminium composites such as metallic conductivity with a coefficient of expansion that can be tailored down to zero, add to their prospects in aerospace and avionics (Sagail, A. and Leisk, G., 1992). 
The age-hardening characteristics of an alloy are generally modified by the introduction of reinforcement. These modifications are due to the manufacturing process, the reactivity between the reinforcement and the matrix, the size, the morphology and volume fraction of the reinforcement (Sagail, A., Leisk, G., 1992; Rajan, T.V. and Sharma, C.P, 1988).

In contrast to this extensive data available on the heat treatment of Al-Si-Fe alloys with convectional alloying elements (Yaro, S.A., et al. 2006). Relatively little is demanded for their ageing hardening characteristics particularly in Silicon carbide reinforcement (Aigbodion, V.S., 2007). Hence, there is need for research to be carried out in this very important area. The aims of the present research are to determine the microstructure and thermal ageing characteristics of $\mathrm{Al}-\mathrm{Si}-\mathrm{Fe} / \mathrm{SiC}$ particulate composites with a view to obtaining the optimum thermal age hardening procedure that would enable the achievement of the desired mechanical properties.

\section{Experimental Procedure}

\subsection{Materials}

The experimental materials used in this study included: silicon carbide with an average particle size of $10 \mu \mathrm{m}$, ferrosilicon, high purity aluminium electrical wire obtained from Northern Cable Company NOCACO (Kaduna), moulding boxes, silica sand, and bentonite obtained from National Metallurgical Development Centre, Jos, Nigeria.

\subsection{Equipment}

The equipment used in this study included: pyrometer, mechanical stirrer, a crucible, an electrical resistance furnace, a Rockwell hardness tester, a Charpy impact machine, a Tinus Olsen tensile machine and a Metallurgical microscope with a built-in camera.

\section{Methods of Sample Production}

The synthesis of the metal matrix composite that was used in this research was achieved using a double stircasting method at the Foundry Shop of the National Metallurgical Development Center, Jos, Nigeria. The samples were produced by keeping the percentage of iron and silicon constant, reinforced with Silicon carbide particles of $10 \mathrm{wt} \%$ and $20 \mathrm{wt} \%$. High-purity aluminium electrical wires was charged in a graphite crucible kept in an electric resistance furnace and $0.01 \% \mathrm{NaCl}-\mathrm{KCl}$ powder were used as a cover for melting the alloy in order to minimize oxidation of aluminium by excluding oxygen and creating a protective atmosphere inside the furnace. After the melting of the pure aluminium, the temperature of the furnace was raised to $720^{\circ} \mathrm{C}$ for the purpose of superheating the aluminium melt. The required quantity of $2.8 \%$ silicon and $0.8 \%$ iron was added to the melt using ferrosilicon, and the melt was thoroughly stirred (Aigbodion, V.S., 2007; Aigbodion, V.S. and Hassan, S.B., 2007).
With progressive melting, the furnace temperature was raised to $780^{\circ} \mathrm{C}$ and the melt was held at this temperature for 10 minutes. The melt was then skimmed to remove the oxides and impurities. The molten metal was continuously stirred in order to ensure a near-uniform distribution of alloying elements and prevent the elements from settling at the bottom due to their higher density. For each melting, 200g of charge materials was used to produce the alloy. The Silicon carbide particles were preheated to $1000^{\circ} \mathrm{C}$, to make their surface oxidized (Aigbodion, V.S. and Hassan, S.B., 2007).

The alloy was then cooled down to a temperature just below the liquidus point $\left(580^{\circ} \mathrm{C}\right)$ to keep the slurry in a semi-solid state. At this stage the preheated SiC particles were added and mixed manually. Manual mixing was used because it was very difficult to mix using automatic device when the alloy was in a semi-solid state. After manual mixing was done, the composite slurry was reheated to a temperature of $720^{\circ} \mathrm{C}$ and then automatic mechanical mixing was carried out for about 20 minutes at an average stirring speed of $150 \mathrm{rpm}$. In the final mixing processes, the furnace temperature was controlled between 730 and $740^{\circ} \mathrm{C}$ and the pouring temperature was controlled to about $720^{\circ} \mathrm{C}$ (Aigbodion, V.S., 2007; Aigbodio, V.S and Hassan, S.B., 2007). A preheated sand mould with diameter $18 \mathrm{~mm}$ and $300 \mathrm{~mm}$ length was used to produce cast bars. After casting, the samples were machined into tensile, impact and hardness test specimens for the purpose of determining the mechanical properties.

\section{Heat Treatment of the Samples}

The test samples were solution heat-treated at temperature of $500^{\circ} \mathrm{C}$ in an electrically heated furnace, soaked for 3 hours at this temperature and then rapidly quenched in warm water at $65^{\circ} \mathrm{C}$. Thermal ageing of the test samples was carried out at temperatures of 100, 200 and $300^{\circ} \mathrm{C}$, for various ageing times of 60 to 660 minutes, and then cooled in air. The thermal ageing characteristic of these grades of composites was evaluated using hardness values obtained from solution heat-treated samples of the investigated composites subjected to the aforementioned temperature conditions. The tensile and impact tests were conducted at the peak ageing time of the various ageing temperatures (Aigbodion, V.S., 2007; Rajan, T.V. and Sharma , C.P., 1988).

\section{Determination of Hardness Values}

The hardness values of the samples were determined according to the provisions in ASTM E18-79 using the Rockwell hardness tester on "B" scale (Frank Well test Rockwell Hardness Tester, model 38506) with a $1.56 \mathrm{~mm}$ steel ball indenter, minor load of $10 \mathrm{~kg}$, major load of $100 \mathrm{~kg}$ and hardness value of $101.2 \mathrm{HRB}$ as the standard block. Before the test, the mating surfaces of the indenter, plunger rod and test samples were thoroughly cleaned by removing dirt, scratches and oil and the testing machine 
Table 1. Hardness (HRB) values for as-cast and thermal age-hardened with $10 \mathrm{wt} \%$ and $20 \mathrm{wt} \%$ of silicon carbide

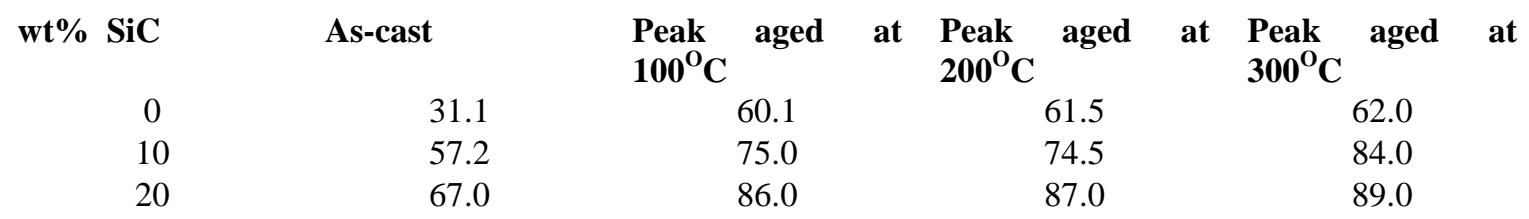

Table 2. Yield strength of Al-Si/SiC composites with $10 \mathrm{wt} \%$ and $20 \mathrm{wt} \%$ of silicon carbide

$\begin{array}{ccccc}\text { Wt\% SiC } & \text { As-cast }\left(\mathbf{N} / \mathbf{m m}^{2}\right) & \begin{array}{c}\text { Peak aged at } \\ \mathbf{1 0 0}^{\mathbf{O}} \mathbf{C}\left(\mathbf{N} / \mathbf{m m}^{\mathbf{2}}\right)\end{array} & \begin{array}{c}\text { Peak aged at } \\ \mathbf{2 0 0}^{\mathbf{O}} \mathbf{C}\left(\mathbf{N} / \mathbf{m m}^{\mathbf{2}}\right)\end{array} & \begin{array}{c}\text { Peak aged at } \\ \mathbf{3 0 0}^{\mathbf{O}} \mathbf{C}\left(\mathbf{N} / \mathbf{m m}^{2}\right)\end{array} \\ 0 & 45.60 & 59.90 & 56.40 & 52.40 \\ 10 & 68.46 & 73.35 & 75.00 & 73.00 \\ 20 & 79.98 & 80.75 & 82.50 & 80.34\end{array}$

Table 3. Tensile strength of Al-Si-Fe/SiC composites with $10 \mathrm{wt} \%$ and $20 \mathrm{wt} \%$ of silicon carbide

\begin{tabular}{|c|c|c|c|c|}
\hline Wt \% SiC & As-cast $\left(\mathrm{N} / \mathrm{mm}^{2}\right)$ & $\begin{array}{c}\text { Peak aged at } 100^{\circ} \mathrm{C} \\
\left(\mathrm{N} / \mathrm{mm}^{2}\right)\end{array}$ & $\begin{array}{c}\text { Peak aged at } \\
200^{\circ} \mathrm{C}\left(\mathrm{N} / \mathbf{m m}^{2}\right)\end{array}$ & $\begin{array}{c}\text { Peak aged at } \\
300^{\circ} \mathrm{C}\left(\mathrm{N} / \mathrm{mm}^{2}\right)\end{array}$ \\
\hline 0 & 58.69 & 62.50 & 67.18 & 64.20 \\
\hline 10 & 96.06 & 98.50 & 98.50 & 100.20 \\
\hline 20 & 106.12 & 120.43 & 125.00 & 121.85 \\
\hline
\end{tabular}

was calibrated using the standard block. The samples were placed on anvils, which acted as support for the test samples. A minor load of $10 \mathrm{~kg}$ was applied to the sample in a controlled manner without inducing impact or vibration and the zero datum position was established. The major load of $100 \mathrm{~kg}$ was then applied, and the reading was taken when the large pointer came to rest or had slowed appreciably and dwelled for up to 2 seconds. The load was then removed by returning the crank handle to the latched position and the hardness value read directly from the semi automatic digital scale. Three indentations were taken and the average represents the hardness values (Aigbodion, V.S., 2007 and Metal handbook., 1985).

\section{Determination of the Tensile Properties}

The tensile properties of the as-cast and peaking thermal ageing samples were conducted on Tinus-Olsen tensile testing machine with a strain rate of $.002 \mathrm{~S}^{-1}$. The test pieces were machined to the standard shape and dimensions as specified by the American Society for Testing and Materials (Annual Books of ASTM Standards, 1990). The sample was locked securely in the grips of the upper and lower crossbeams of the testing machine. A small load was initially applied to seat the sample in the grips and then the load was increased until failure occurred.

\section{Impact Strength Determination}

The impact test of the as-cast and peaking thermal ageing samples was conducted using a fully instrumented Avery Denison test machine. The mass of the hammer was $227 \mathrm{~kg}$ and the striking velocity was $3.5 \mathrm{~m} / \mathrm{sec}$. Charpy impact tests were conducted on notched samples. Standard square impact test sample measuring $75 \mathrm{x} 10 \mathrm{x}$
$10 \mathrm{~mm}$ with notch depth of $2 \mathrm{~mm}$ and a notch tip radius of $0.02 \mathrm{~mm}$ at an angle of $45^{\circ}$ was used (Annual Books of ASTM Standards, 1990).

Before the test sample was mounted on the machine, the pendulum was released to calibrate the machine. The test samples were then gripped horizontally in a vice and the force required to break the bar was released from the freely swinging pendulum. The value of the angle through which the pendulum had swung before the test sample was broken corresponded with the value of the energy absorbed in breaking the sample and this was read from the calibrated scale on the machine (Annual Books of ASTM Standards, 1990).

\section{Microstructural Examination}

Metallographic samples were cut from the produced samples. The cut samples were then mounted in Bakelite, and mechanically ground progressively on grades of $\mathrm{SiC}-$ impregnated emery paper (80-600 grits) sizes using water as the coolant. The ground samples were then polished using one-micron size alumina polishing powder suspended in distilled water. Final polishing was done using 0.5 micron alumina polishing powder suspended in distilled water. Following the polishing operation, etching of the polished specimen was done using Keller's reagent. The structure obtained was photographically recorded using an optical microscope with built-in camera (Aigbodion, V.S., 2007; Aigbodion, V.S. and Hassan. S.B., 2007).

\section{Results and Discussion}

\subsection{Results}

The various microstructures developed for the two grades of composites in the as-cast and thermally age- 


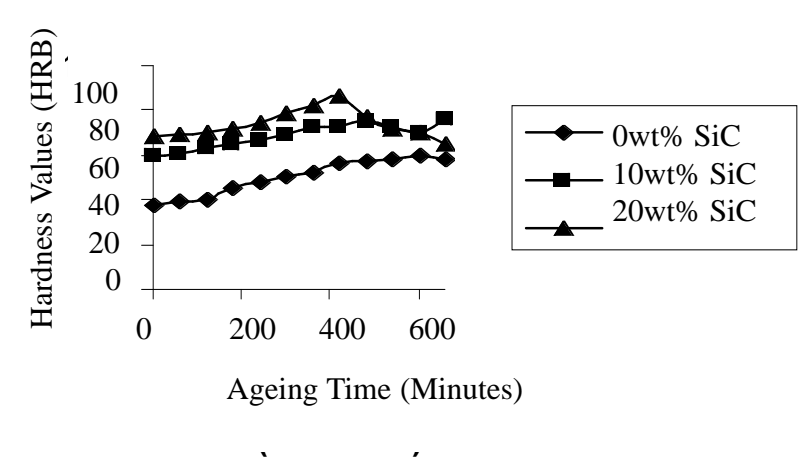

Figure 1. Variation of hardness values with ageing time at aageing temperature of $100^{\circ} \mathrm{C}$

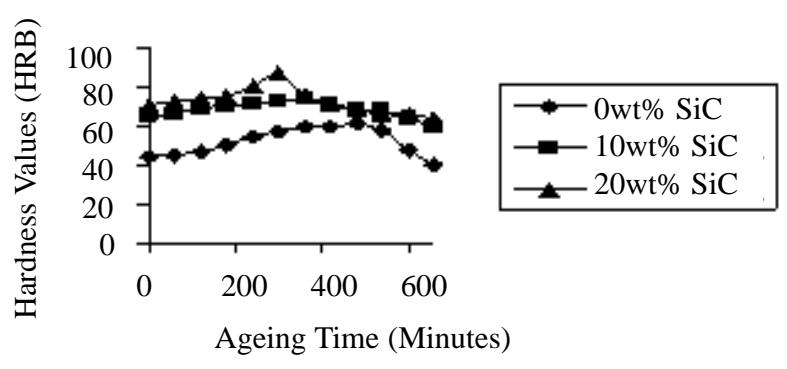

Figure 2. Variation of hardness values with ageing time at ageing temperature of $200^{\circ} \mathrm{C}$

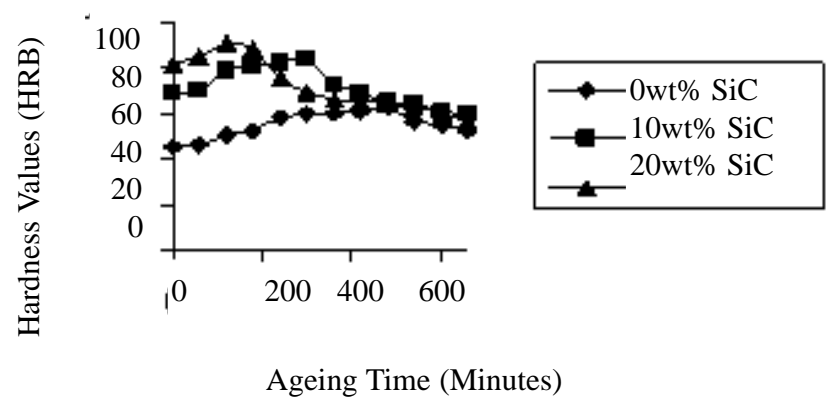

Figure 3. Variation of hardness values with ageing time at ageing temperature of $300^{\circ} \mathrm{C}$

hardened condition are shown in Micrographs 1-12. The thermal ageing response measured by the variation of hardness with time for two grades of composites is shown in Figs. 1-3. Table 1shows the hardness values of both the thermally as-cast and age-hardened $\mathrm{Al}-\mathrm{Si}-\mathrm{Fe} / \mathrm{SiC}$ composites. The results of yield strength and ultimate tensile strength with weight fraction of Silicon carbide at various ageing temperatures are shown in Tables 2-3. The results of impact energy with weight fraction of Silicon carbide ( $\mathrm{SiC}$ ) at various ageing temperatures are shown in Table 4.

\section{Discussions}

\subsection{Thermal Ageing Characteristics of Al-Si-Fe/ SiC Composites}

From Figs. 1-3, it can be seen that there is a steep rise in the hardness values of each grade of the composite at initial stages for all ageing temperatures and then a fall after reaching the various peak ageing times are reached, corresponding to over-ageing. However, at higher ageing temperature the materials developed peak hardness at shorter ageing time, because the rate of precipitation of the second phase materials is faster and hence increases in hardness values. The time to obtain peak hardness is shorter according to the sequence: $100^{\circ} \mathrm{C}>200^{\circ} \mathrm{C}>$ $300^{\circ} \mathrm{C}$ (See Figs. 1-3).

The thermal age-hardening behavior of the Al-Si$\mathrm{Fe} / \mathrm{SiC}$ particulate composites are similar to $\mathrm{Al}-\mathrm{Si}-\mathrm{Mg} / \mathrm{SiC}$ particulates as reported by Cottu et al. (1992) ie. hardness continuously increases to a maximum during thermal ageing and then decreases later due to over ageing. It is interesting to note that in the reinforced aluminium alloy metal-matrix, as the volume fraction of $\mathrm{SiC}$ increase to $20 \mathrm{wt} \%$ in the aluminium alloy there is a monotonic reduction in the time required to reach peak hardness (See Fig. 3).

The 20wt\%SiC addition, yielded the highest hardness value. As far as hardening behavior of the composites is concerned, particle addition in the matrix alloy increases the strain energy in the periphery of the particles in the matrix and these tendencies may be due to the formation of the dislocation at the boundary of the ceramic particles by the difference in the thermo-expansion coefficient between the matrix and ceramic particles during solution treatment and quenching since a lot of dislocations generate in the main matrix/particle interface (Bedir, F., 2006). Thus, dislocations cause the hardness increase in composite as well as residual stress increase because it acts as non-uniform nucleation sites in the interface following the age treatment. It is thought that the higher the amount of the ceramic particles in the matrix, the higher the density of the dislocation, and as a result, the higher the hardness of the composite.

\subsection{Microstructural Analysis}

Microstructures of the as-cast and heat-treated composites at various ageing temperatures and peaking ageing time were examined by the use of a metallurgical microscope. They were observed to contain primarily $\alpha-\mathrm{Al}$, silicon eutectic and $\mathrm{SiC}$ particle as shown in Micrographs 112. In the microstructure of the composites Si phase was seen apparently in the eutectic regions, and intermetallic compounds such as $\mathrm{FeSiAl}_{3}$, iron-containing phases due to the secondary alloying elements (Aigbodion, V.S., 2007; Rajan, T.V. and Sharma, C.P, 1988).

The microstructure of the as-cast unreinforced Al-SiFe alloy is shown in Micrograph 1, while Micrographs 23 show the microstructure of the as-cast reinforced alloys with $\mathrm{SiC}$ particles.

The microstructure reveals that there are small discontinuities and a reasonably uniform distribution of SiC particles. The ceramic phase is shown as dark phase, while the metal phase is white. These structures are in agreement with the co-continuous interlaced phases studied by other researchers (Rohatgi, P.K., et al. 1988 and Whitehouse, A.F., 1990). Micrographs 4-12, show the 
The Journal of Engineering Research Vol. 7, No. 1, (2010) 53-61

Table 4. Impact energy for as-cast and age-hardened with 10wt\# and 20wt\# of silicon carbide

\begin{tabular}{|c|c|c|c|c|}
\hline Wt\% SiC & As-cast & $\begin{array}{l}\text { Peak aged at } \\
\qquad 100^{\circ} \mathrm{C}\end{array}$ & $\begin{array}{l}\text { Peak aged at } \\
200^{\circ} \mathrm{C}\end{array}$ & $\begin{array}{l}\text { Peak aged at } \\
\quad 300^{\circ} \mathrm{C}\end{array}$ \\
\hline 0 & $17.0 \mathrm{~J}$ & 28.0J & 24.0J & 22.0J \\
\hline 10 & $14.5 \mathrm{~J}$ & $20.0 \mathrm{~J}$ & $19.0 \mathrm{~J}$ & $19.0 \mathrm{~J}$ \\
\hline 20 & $12.0 \mathrm{~J}$ & $17.0 \mathrm{~J}$ & $15.5 \mathrm{~J}$ & $16.0 \mathrm{~J}$ \\
\hline
\end{tabular}

microstructure of the thermally age-hardened Al-Si$\mathrm{Fe} / \mathrm{SiC}$ composites. The microstructure reveals the dissolution and distribution of the $\mathrm{SiC}$ particles in the metal matrix and the presence of precipitates at the particles matrix interfaces with precipitation and dissolution of the $\mathrm{SiC}$ particles and silicon eutectic phase (Aigbodio, V.S., 2007; Aigbodion, V.S. and Hassan, S.B., 2007).

The formation and presence of precipitates at the particles- matrix interfaces may be appreciated by comparing micrographs of the composite in the as-cast state micrographs 1-3 and in the peak age-hardened state micrographs 4-12. The micrographs in the peak age-hardened state reveal precipitates covering the surface at the particles-matrix interfaces. Cottu et al. (1992) reported a similar behavior of increased precipitation at interfaces for aluminum alloy 6061 reinforced with whiskers of silicon carbide.

\subsection{Hardness Value}

From Table 1, the hardness values for thermally as-cast and age-hardened composite increases as the percentage of Silicon carbide increases from $10 \mathrm{wt} \%$ to $20 \mathrm{wt} \%$ in the alloy. This is due to an increase in the percentage of the hard and brittle phase of the ceramics body in the alloy.

The hardness values of the thermally age-hardened alloy are almost equal at various ageing temperatures with percentage SiC additions (See Table 1), in line with the earlier observation of (Cottu et al. 1992 and Ikechukwuka 1997).

\subsection{Yield and Tensile Strength}

From Tables 2-3, the yield strength and ultimate tensile strength of both the as-cast and age-hardened composites increased with the increased percentage silicon carbide to $20 \mathrm{wt} \% \mathrm{SiC}$. The as-cast samples have a value of 79.98 and $106.12 \mathrm{~N} / \mathrm{mm}^{2}$ for yield and tensile strength at $20 \%$ $\mathrm{SiC}$ addition.

For the thermally age-hardened samples, similar trends were also observed as for the case of the as-cast samples, in that the yield strength and ultimate tensile strength increased to $20 \%$ wt of SiC. The ultimate tensile strengths of the thermally age-hardened samples at $20 \mathrm{wt} \% \mathrm{SiC}$ are $120.43,125.00$ and $121.85 \mathrm{~N} / \mathrm{mm}^{2}$ at peak ageing of 100 , 200 and $300^{\circ} \mathrm{C}$ respectively. (See Table 3). Also the yield strengths of age-hardened samples at $20 \mathrm{wt} \% \mathrm{SiC}$ addition are $80.75,82.50$ and $80.34 \mathrm{~N} / \mathrm{mm}^{2}$ at peak ageing of 100 , 200 and $300^{\circ} \mathrm{C}$ respectively (See Table 2 ).

The higher values of both ultimate tensile strength and yield strength obtained at $20 \mathrm{wt} \% \mathrm{SiC}$ are attributed to the uniform distribution of the $\mathrm{SiC}$ particles in the microstructure of the $20 \mathrm{wt} \% \mathrm{SiC}$ (See Micrographs 3, 10-12). It can be seen that the inter-particle distance is smaller. The contribution of inter-particle distance to strain hardening arises from the fact that the space permitted a dislocation to maneuver round obstacles limits the yield stress given by the formula (Dieter, G.E., 1988):

$$
\begin{gathered}
\hat{o}=\frac{G b}{\lambda} \cdot \hat{o}=\text { Yield stress, } \ddot{e}=\text { Inter-particle distance, } \\
\mathrm{G}=\text { Shear energy of dislocation and } \mathrm{b}=\text { Burger vector. }
\end{gathered}
$$

The smaller the values of $\lambda$ the greater the yield stress as a result of strain hardening. It therefore supports the fact that (Micrographs 3,10-12) with smaller $\lambda$.

A substantial increase in both the yield strength and ultimate tensile strength was obtained when compared with the results of as-cast samples. For example the yield strength of Al-Si-Fe/10SiC particles increased from 68.46 to $75.00 \mathrm{~N} / \mathrm{mm}^{2}$, while the ultimate tensile strength increased from 96.06 to $98.50 \mathrm{~N} / \mathrm{mm}^{2}$ in the as-cast and peak age-hardened at $200^{\circ} \mathrm{C}$ respectively. The yield and tensile strength of Al-Si-Fe/20SiC particles also increased from 79.98 to $82.50 \mathrm{~N} / \mathrm{mm}^{2}$ and 106.12 to $125.00 \mathrm{~N} / \mathrm{mm}^{2}$ in the as-cast and thermally age-hardened at $200^{\circ} \mathrm{C}$ temperature (See Tables 2-3).

These results show that the $\mathrm{Al}-\mathrm{Si}-\mathrm{Fe} / 10 \mathrm{SiC}$ particles samples has $9.55 \%$ and $2.54 \%$ increases in yield strength and ultimate tensile strength respectively over those of the as-cast samples at peak ageing at $200^{\circ} \mathrm{C}$, while for the Al$\mathrm{Si}-\mathrm{Fe} / 20 \mathrm{SiC}$ particles the respective increments were $3.15 \%$ and $17.79 \%$ for yield strength and ultimate tensile strength. The increase in strength of the thermally agehardened samples over those of the as-cast are attributed to the uniform distribution of $\mathrm{SiC}$ in the aged samples than the as-cast samples respectively (See Micrographs 1 and 3 and Micrographs 4-12).

Sagail and Leisk (1992) and Whitehouse et al. (1991) attributed this to an increase in dislocation density at the interfaces. An increase in dislocation density strain hardens the metal-matrix locally and provides heterogeneous nucleation sites for precipitation, thereby accelerating the ageing response. The modulated structures formed during ageing in these grades of composites enhanced these properties and this is in agreement with the earlier works on Al-Si-Mg/SiC (Cottu, J.P. et al. 1992 and Ikechukwuka. N.A, 1997). The addition of SiC particles affects not only the precipitation kinetics but also the relative amounts of the various phases present in the microstructure. Besides during quenching from the solution heat treatment temperature, the SiC particles cool more slowly than the matrix (since the particles have a lower thermal conductivity). This causes the matrix around the particles to be 


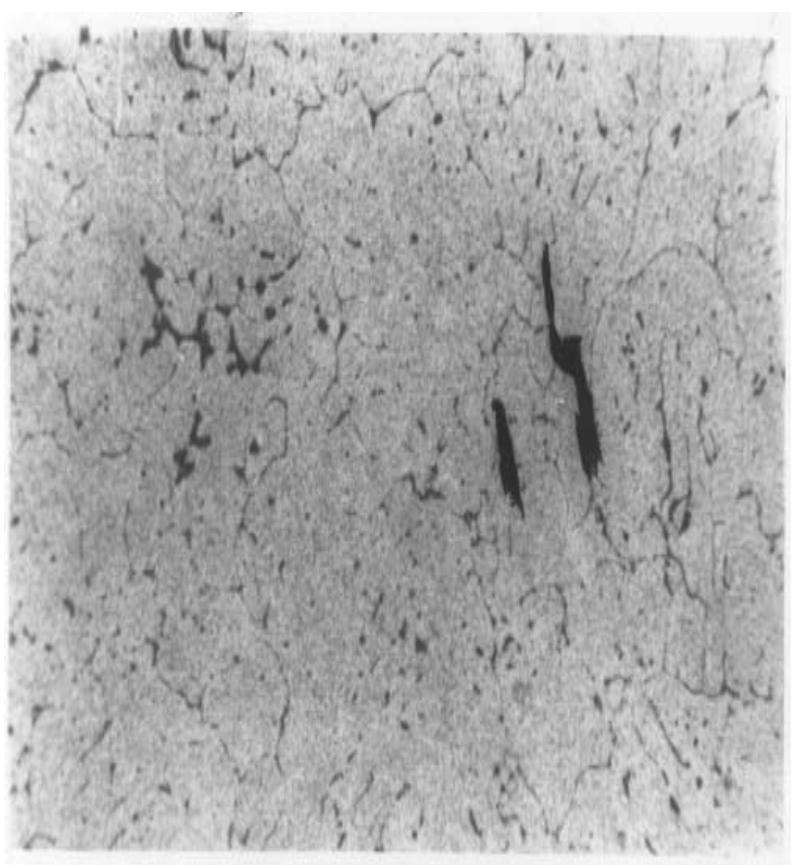

Micrograph 1. Microstructure of the Al-Si-Fe alloy, showing silicon eutectic (black) containing $\mathrm{FeAl}_{3} \mathrm{Si}$ phases and $\alpha-\mathrm{Al}$ (white) (x200). The structure reveals the eutectic silicon containing $\mathrm{FeSiAl}_{3}$ phase in aluminium matrix.

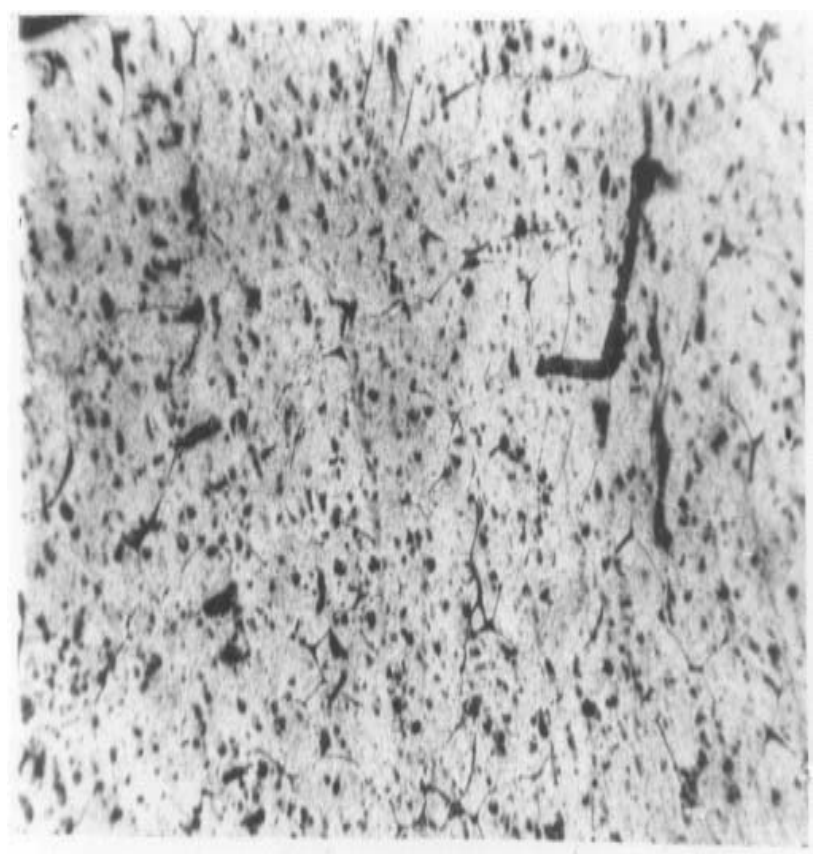

Micrograph 2. Microstructure of the Al-Si-Fe alloy with $10 \mathrm{wt} \%$ of $\mathrm{SiC}$ the the structure reveals the dissolution of the eutectic silicon phase and uniform distribution of $\mathrm{SiC}$ (black) in $\alpha-\mathrm{Al}$ matrix (white) (x200).

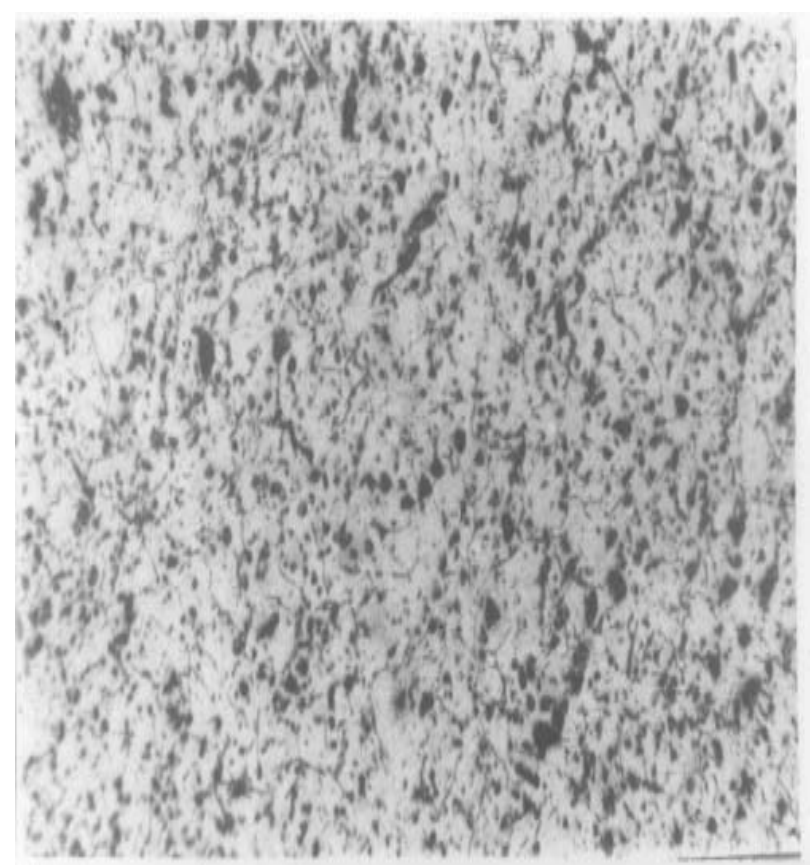

Micrograph 3. Microstructure of Al-Si alloy reinforced with 20 wt \% of SiC. The structure reveals and dissolution of the eutectic silicon phase and uniform distribution of $\mathrm{SiC}$ (black) in $\alpha$-Al matrix (white) (x200).

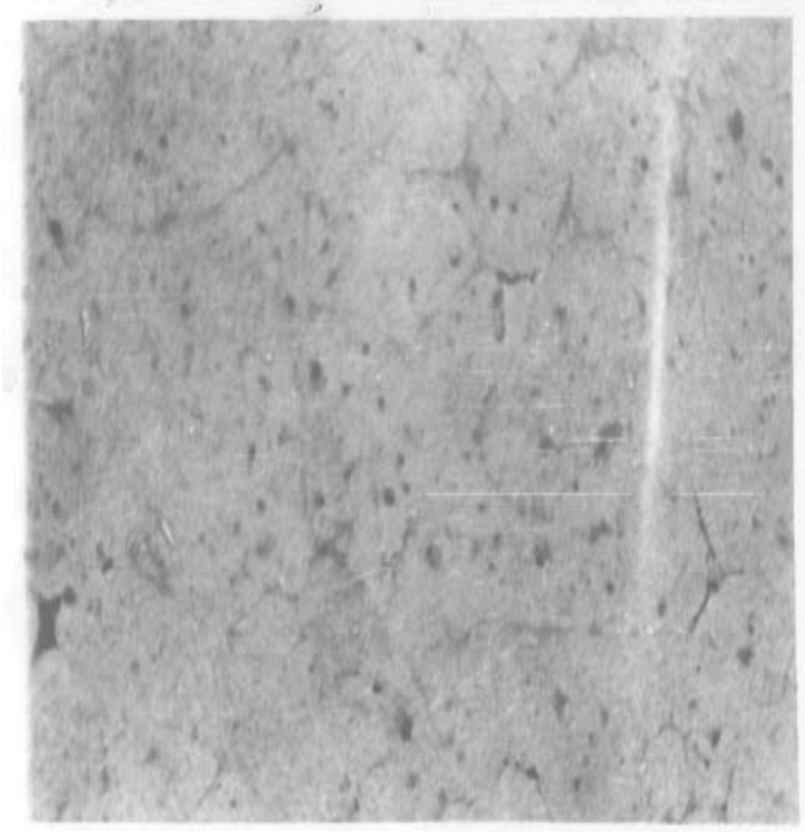

Micrograph 4. Microstructure of the Al-Si-Fe alloy after peak aged at $1^{\circ} \mathrm{C} C(\mathrm{x} 200)$. The structurre reveals dissolution and precipitation of the silicon eutectic (black) and the $\mathrm{FeAl}_{3} \mathrm{Si}$ phases in $\alpha-$ Al matrix (white). 


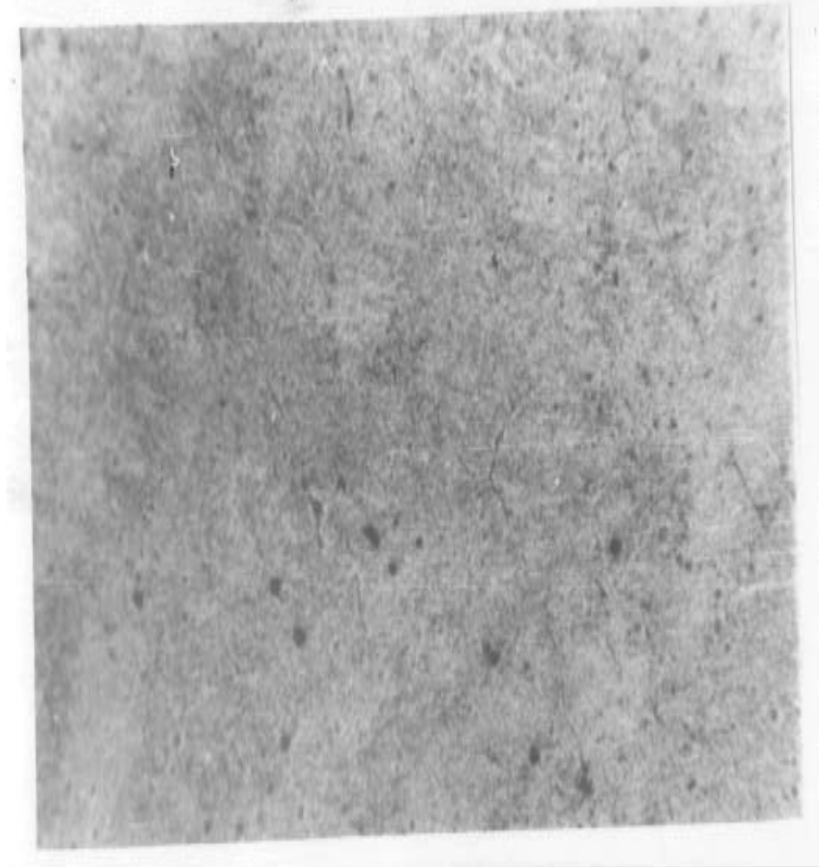

Micrograph 5. Microstructure of the Al-Si-Fe alloy after peak aged at $2000 \mathrm{C}(\mathrm{x} 200)$. The structure reveals uniform dissolution and precipitation of the silicon eutectic (black) and the $\mathrm{FeAl}_{3}$ Sui phases in $\alpha$-al matrix (white).

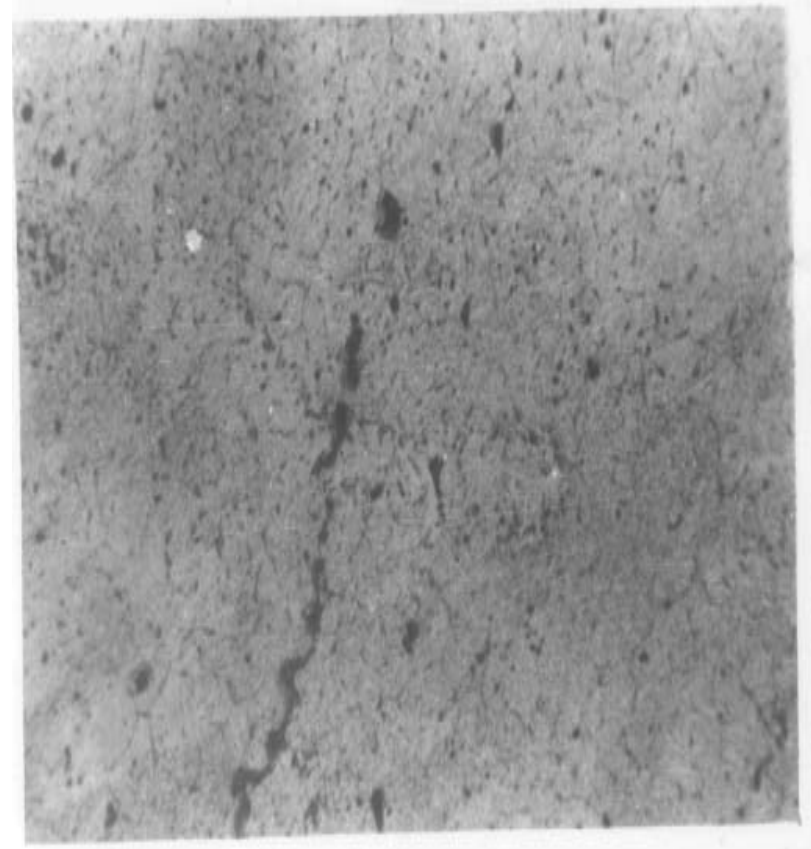

Micrograph 6. Microstructure of the unreinforced alloy after peak aged at $300^{\circ} \mathrm{C}(\mathrm{x} 200)$. The structure reveals dissolution and precipitation of the silicon eutectic (black) and the $\mathrm{FeAl}_{3} \mathrm{Si}$ phases with some segregation of silicon eutectic phases in $\alpha$-Al matrix (white).

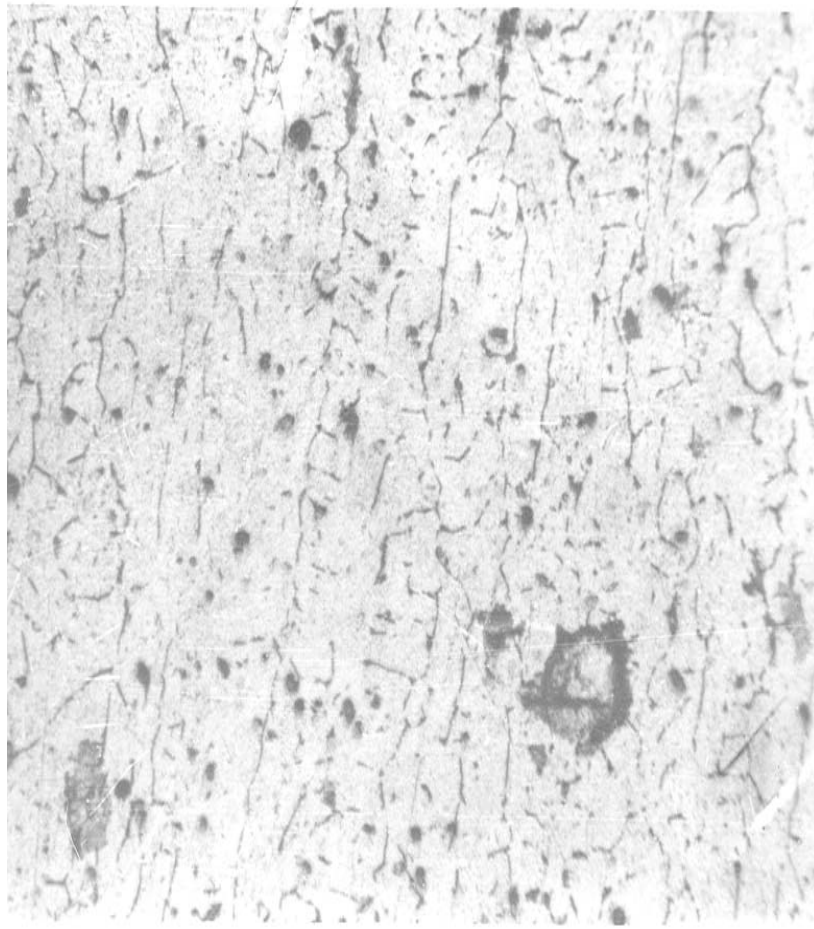

Micrograph 7. Microstructure of the reinforced alloy (10 wt \% of $\mathrm{SiC})$ after peak aged at $1000 \mathrm{C}(\mathrm{x200})$. The structure reveals the dissolution of the eutectic silicon phase and uniform distribution of SiC (black) in $\alpha$-Al matrix (white).

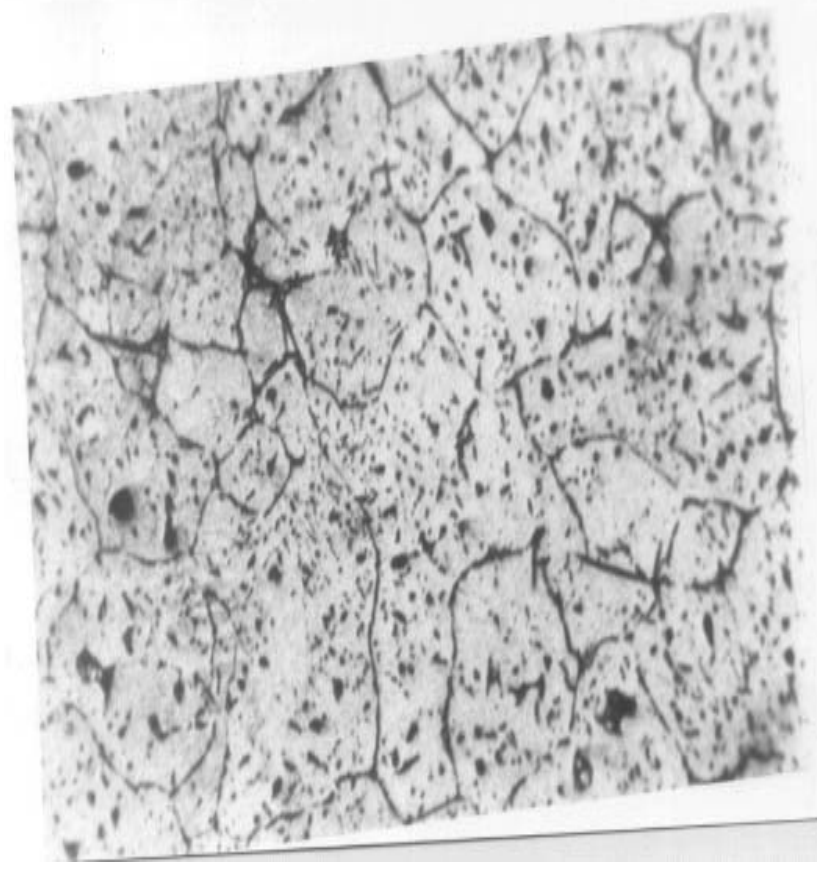

Micrograph 8. Microstructure of the reinforced alloy $\left(10 \mathrm{wt} \%\right.$ after peak aged at $200^{\circ} \mathrm{C}$ (x200). The structure reveals the dissolution of the eutectic silicon phase and distribution of SiC (black) in $\alpha$-Al matrix (white). 


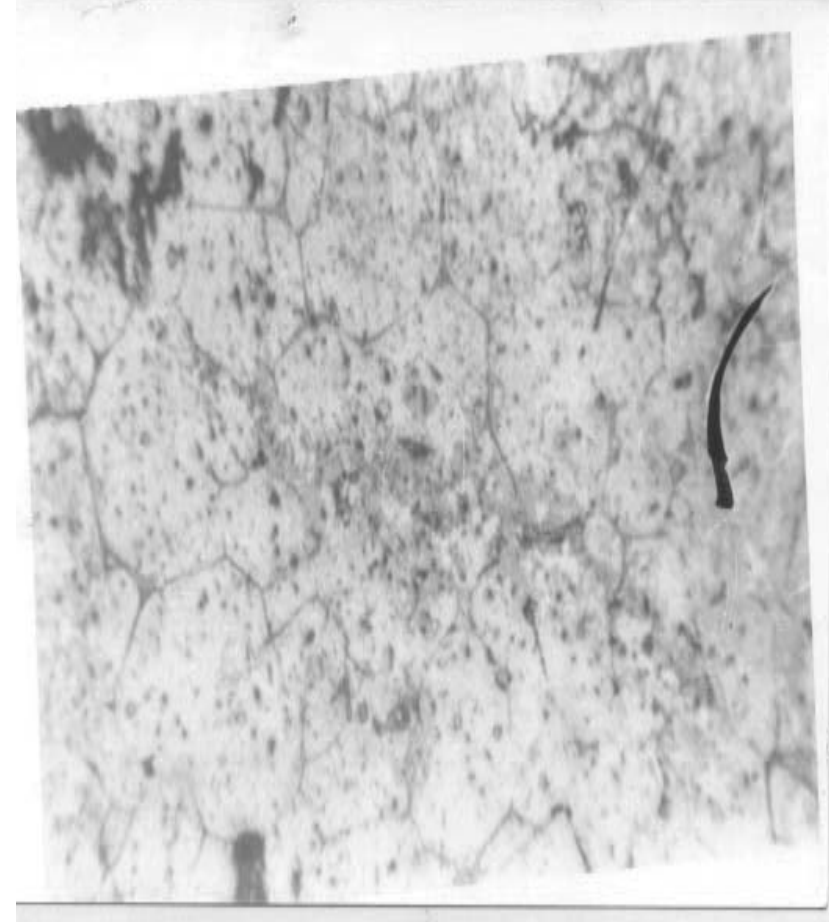

Micrograph 9. Microstructure of the reinforced alloy (10 wt \% of SiC after peak aged at $300^{\circ} \mathrm{C}$ (x200). The structure reveals the dissolution of the eutectic silicon phase and uniform distribution of SiC (black) with precipitation of the SIC particles.

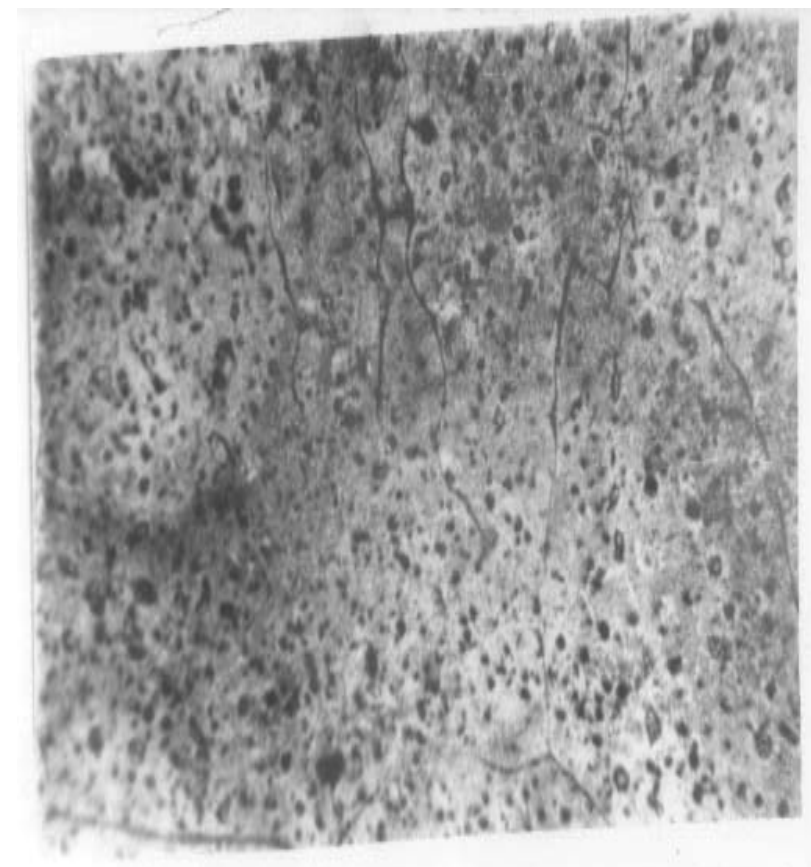

Micrograph 10. Microstructure of the reinforced alloy (20 wt \% of $\mathrm{SiC}$ ) after peak aged at $100^{\circ} \mathrm{C}(\mathrm{x} 200)$. The structure reveals the dissolution of the eutectic silicon phase and uniform distribution of SiC (black) with precipitation covering.

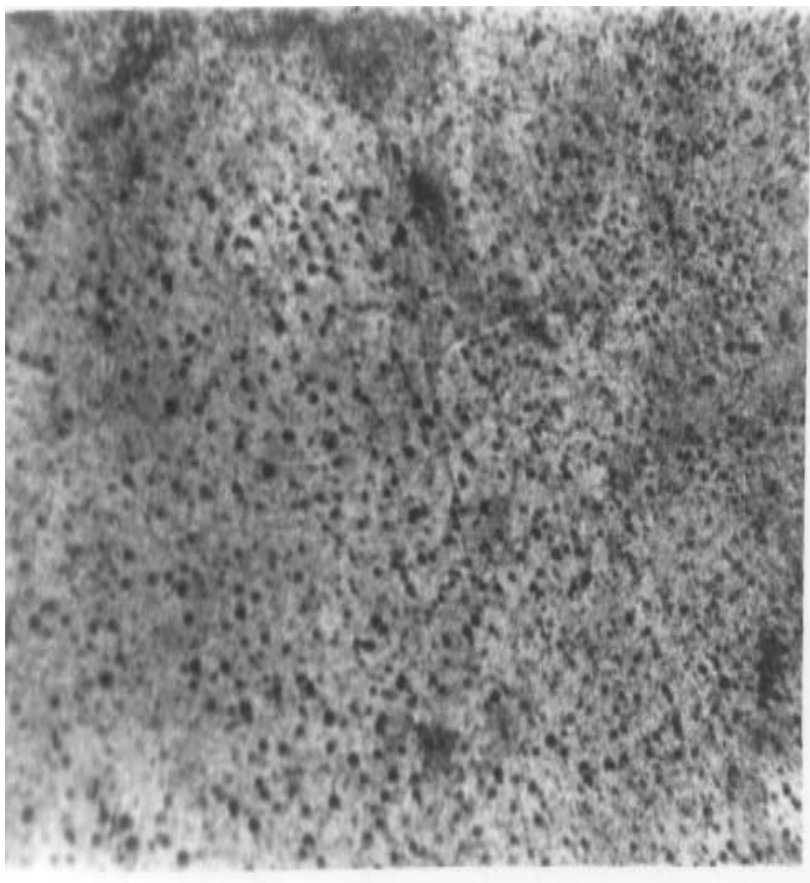

Micrograph 11. Microstructure of the reinforced alloy (20 wt\% of $\mathrm{SiC}$ ) after peak aged at $2000 \mathrm{C}(\mathrm{x} 200)$. The structure reveals the dissolution of the eutectic silicon phase and well uniformly distribution of SiC (black) with precipitation covering the aluminium phase (white).

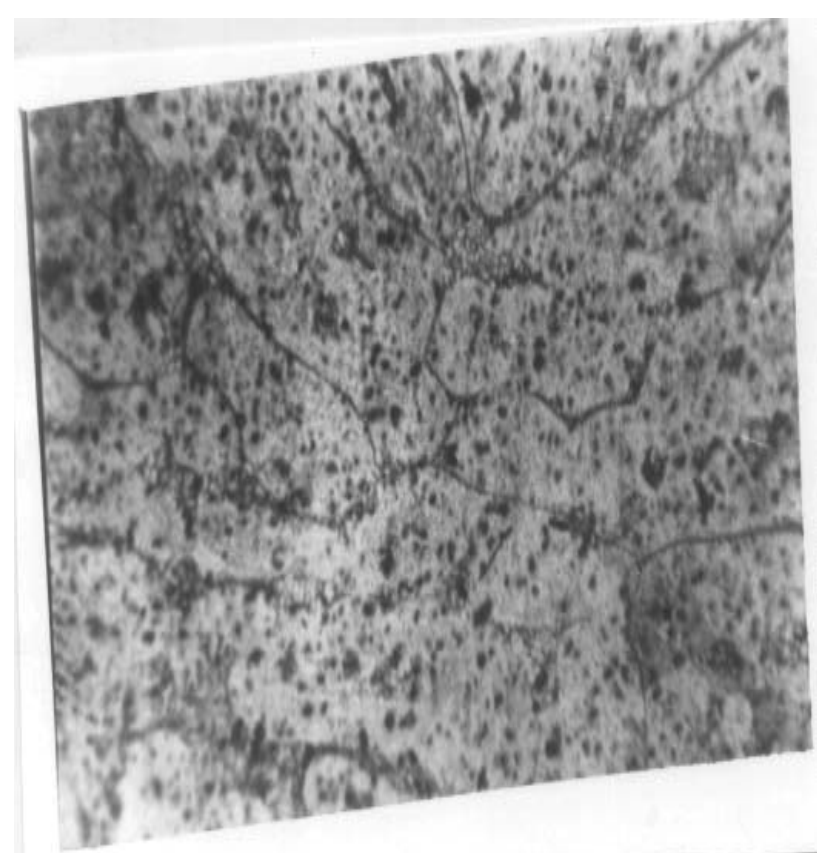

Micrograph 12. Microstructure of the reinforced alloy (20 wt \% of $\mathrm{SiC}$ ) after peak aged at $3000 \mathrm{C}(\mathrm{x} 200)$. The structure reveals the dissolution of the eutectic silicon phase and uniform distribution of SiC (black) with precipitation covering. 
warmer than the bulk matrix. The high dislocation density and the high solubility centers (the warm particlesmatrix interfaces) in the composite are favorable conditions for precipitation formation. This mechanism is a possible explanation for the higher volume fraction of precipitates obtained in the composite of the age hardening condition (Aigbodion, V.S., 2007; Aigbodion, V.S. and Hassan, S.B., 2007).

\subsection{Impact Energy}

From the Table 4, the impact energy of both the as-cast and age-hardened samples, decreased as the percent $\mathrm{SiC}$ addition increases in the alloy. The brittle nature of the reinforcing materials $(\mathrm{SiC})$ plays a significant role in degrading the impact energy of the composite, since the unreinforced alloy and the alloy with $10 \mathrm{wt} \% \mathrm{SiC}$ particles have the highest impact energy, indicating that they are the toughest of them all (Aigbodion, V.S., 2007).

\section{Conclusions}

From the results of the investigations, the following conclusions have been made:

1) The uniform distribution of the $\mathrm{SiC}$ particles in the microstructure of both the as-cast and thermally agehardened $\mathrm{Al}-\mathrm{Si}-\mathrm{Fe} / \mathrm{SiC}$ composites is the major factor responsible for the improvement in the mechanical properties.

2) The addition of SiC particles affects not only the precipitation kinetics but also the relative amounts of the various phases present in the microstructure, and that during quenching from the solution heat treatment temperature, the SiC particles cool more slowly than the matrix (since the particles have a lower thermal conductivity). This causes the matrix around the particles to be warmer than the bulk matrix. The high dislocation density and the high solubility centers (the warm particles-matrix interfaces) in the composite are favorable conditions for precipitation formation. This mechanism is a possible explanation for the higher volume fraction of precipitates obtained in the composite of the age-hardening condition.

3) This research therefore, has established that these grade of composites respond to precipitation-hardening heat treatment.

\section{References}

Aigbodion, V.S., 2007, "Development of Al-Si-Fe/SiC Particulate Composite as advanced Materials for
Engineering Applications,” M.Sc Thesis, Department of Metallurgical Engineering, Ahmadu Bello University, Zaria, Nigeria, pp. 45-50.

Aigbodion,V.S. and Hassan, S.B., 2007, “ Effect of Silicon Carbide Reinforcement on Microstructure and Properties of cast Al-Si-Fe/SiC Particulate Composites,” Materials Science and Engineering A: 447, pp. 355-360.

Annual Books of ASTM Standards, 1990, Section 1. Iron and Steel Products, Vol. 261 01.04, pp. 13-63.

Bedir, F., 2006, "Fabrication of Two Layered Al-B4C Composites by Conventional Hot Pressing under Nitrogen Atmosphere and their Characterization," J. of Mech.Sci. and Tech. KSME, Vol. 20(7), pp. 10021011

Clyne, T.W., (ed.), 2000, "Comprehensive Composite Materials," Vol. 3, Metal Matrix Composites (ser. eds), pp. 1-8.

Cottu, J.P., Coudere, J.J., Viguier, B. and Bernard, L., 1992, “ J. Mater Sci 27,” pp. 3068-3074.

Dieter.G.E., 1988, “ Mechanical Metallurgy,” McGrawHill Company, pp. 184-223.

Fishman, S.G. and Dhingra, A.K., 1988, “ Reinforced Metal Composites,” Materials Park, OH: ASM International Publication, p. 249.

Ikechukwuka, N.A., 1997, "Characterization of Aluminium Alloy 2618 and Its Composites Containing Alumina Particles," unpublished $\mathrm{PhD}$ thesis Department Mechanical Engineering, University of Askatchewan, Saskatoon, pp. 87-200.

Metals handbook, Mechanical testing, 1985, 9th edition, Vol. 8, American Society for Metals, the United States of America, pp. 250-257

Rajan, T.V. and Sharma, C.P., 1988, "Heat Treatment Principles and Techniques," Published by Prenticehall of India Private Limited, pp. 35-159.

Rohatgi, P.K., Yarandi, F.M. and Liu, Y., Proc. of Inter. Symposium on Advances in Cast.

Sagail, A., Leisk, G., 1992, "Heat Treatment Optimization of Alumina/Aluminium Metal Matrix Composites using the Taguchi Approach," Scripta Metallurgica et Materials, pp. 871-876.

Yaro, S.A., Aigbodion, V.S. and Mohammed, O.Y., "Effects of Copper Addition on the Mechanical Properties of Al-Si-Fe Alloy,” International Research Journal in Engineering \& Technology (IREJEST) FUTO, Owerri, Nigeria, pp. 32-39.

Whitehouse, A.F., Shahani, R. A. and Clyne, T.W., 1991, Metal Matrix Composites: Processing, Microstructure and Properties,” 12, International Symposium Roskilde, N.Hansen et al. eds, Ris $\theta$ National Laboratory, Denmark, pp. 74 1-748. 